\title{
Epidemiology of Spinal Cord Lesions in Denmark
}

\author{
F. Biering-Sørensen, MD, PhD, V. Pedersen, MD, S. Clausen, MD \\ Center for Spinal Cord Injured, Department TH, Righospitalet, University Hos- \\ pital, Denmark.
}

\section{Summary}

Denmark has a population of about $5 \cdot 2$ million. The rehabilitation of spinal cord injured (SCI) takes place in two specialised rehabilitation hospitals. The incidence of new traumatic SCI admitted to these hospitals in the period 1975-1984 was 9.2 per million per year. During this period 92 Danes with non-traumatic and 268 with newly sustained traumatic spinal cord lesions were admitted to the rehabilitation hospital in Hornbak, which uptake area corresponded to South and East Denmark and Greenland and the Faroe Islands. Among the traumatic SCI $47 \%$ were due to traffic accidents, $23 \%$ to falls to a level below, $8 \%$ to attempted suicides, $6 \%$ to shallow water diving, and 6\% to sporting accidents. The number of SCI caused by traffic accidents was found to decrease coincidently with the introduction of general speed limits and compulsory seat belt wearing. The male/female ratio was for the traumatic SCI 3.3, which was significantly lower than in the preceding 10-year period. $40 \%$ of all traumatic SCI were sustained at 15-24 years of age, and 51\% had tetraplegia. Traffic accidents gave rise to more cervical, and falls to more caudal lesions. $41 \%$ of the traumatic SCI had an improvement in their neurological status after their admission to the neurosurgical department until the discharge from the rehabilitation hospital. Those with incomplete lesions showed greater improvement than those with complete lesions regardless of the level. Complete cervical lesions had significant better remissions than complete thoracic/lumbar lesions.

Key words: Spinal cord lesions; Epidemiology; Denmark; Aetiology; Neurological prognosis.

Correspondence and reprint request to Fin Biering-Sørensen, Center for Spinal Cord Injured, Rigshospitalet, Havnevej 25, DK-3100 Hornbæk, Denmark. 


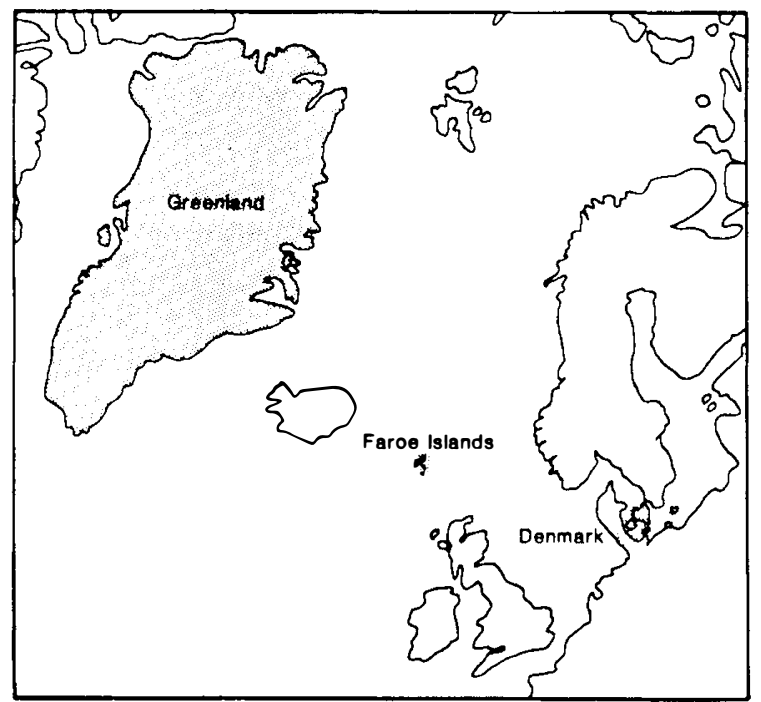

Figure 1 Area for admission to the rehabilitation hospital in Hornbæk, Denmark during the years 1975-1984. Uptake area hatched.

\section{Introduction}

In January 1985, the Danish Kingdom had about 5.2 million inhabitants. A little less than 100000 were living in Greenland and the Faroe Islands; most lived in Denmark, with a population density of some 115 persons per square kilometre.

In the past 30 years SCI patients in the acute phase have usually been admitted to one of the six neurosurgical departments in Denmark, and their rehabilitation has usually been in one of the two special hospitals, i.e. in Hornbæk and Hald Ege (now Viborg) located in East and West Denmark respectively.

The purpose of this study is to present epidemiological data on patients with spinal cord or cauda equina lesions admitted to the rehabilitation hospital in Hornbæk. In addition an estimate of the incidence of traumatic spinal cord injuries in the whole of Denmark will be given.

\section{Materials and methods}

This retrospective study is based on records of all patients with spinal cord lesion admitted to the rehabilitation hospital in Hornbæk, Denmark during the period 1 January 1975 to 31 December 1984. For certain items additional information were included for patients admitted from 1 January 1965 to 31 December 1974. Foreign citizens were only included if they had permanent residence in Denmark at the time of injury.

The area for admission to the rehabilitation hospital in Hornbæk were in the studied period as illustrated in Figure 1, i.e. East and South Denmark, Greenland and the Faroe Islands. Patients requiring respirator support or having progressive spinal cord lesion, e.g. cancer and multiple sclerosis were not admitted, although patients with cancer expected to be cured were accepted. Only 4 children were admitted including those with myelomeningocele. Only patients 
Table I Aetiology of non-traumatic spinal cord lesions

\begin{tabular}{lr}
\hline Disc degeneration/prolapse & 27 \\
Neoplasm & 22 \\
Transverse myelitis & 11 \\
Vascular & 11 \\
Osteomyelitis & 3 \\
Abscess & 3 \\
Arachnoiditis & 2 \\
Spina bifida & 2 \\
Syringomyelia & 2 \\
Other causes & 9 \\
\hline Total & 92 \\
\hline
\end{tabular}

with spinal cord lesions of such severity that specialised treatment was necessary were admitted. Patients who would not be able to co-operate in the rehabilitation programme were not admitted to the rehabilitation hospital in Hornbæk.

During the 10-year period 379 patients were admitted to the rehabilitation hospital in Hornbæk for the first time because of a spinal cord lesion. $92 \mathrm{had}$ a non-traumatic lesion while 19 patients with traumatic spinal cord injuries were either not admitted in continuation of the injury or were foreign citizens without permanent residence in Denmark.

During the same 10-year period we have information (B. Risgaard, personal communication) of 197 patients with traumatic spinal cord injuries who were admitted to the special rehabilitation hospital in Hald Ege, which covered the remaining part of Denmark. Criteria for admission to the hospital in Hald Ege were identical to those for admission to the rehabilitation hospital in Hornbæk.

Information was obtained from Hornbæk on the aetiology and type of the spinal cord lesion. If necessary, a patient interview was carried out. All spinal X-rays were reviewed in an attempt to define the mechanism of injury: these were divided into flexion, flexion-rotation, extension, compression injuries, and direct blow, following the classification of Holdsworth (1970). In some instances it was not possible with reasonable certainty to be certain of the precise mechanism involved.

In agreement with the classification suggested by Frankel et al. (1969) all patients with traumatic spinal cord injuries were classified at the primary admission to the neurosurgical department and at the discharge after rehabilitation by use of the respective records.

The neurological level is given as the last preserved segment.

Fisher's exact test (two-tailed) was used in $2 \times 2$ situations, otherwise have chi-square test been used to evaluate differences between groups, and 5\% was chosen as level of significance.

\section{Results}

Non-traumatic spinal cord lesions

The aetiology of the 92 non-traumatic spinal cord lesions can be seen in Table I. The location of the disc degenerations/prolapses were 11 cervical, 5 thoracic, and 11 lumbar. Among the neoplasms were glioma, astrocytoma and epidermoid 
Non-traumatic spinal cord lesions (1975-84)

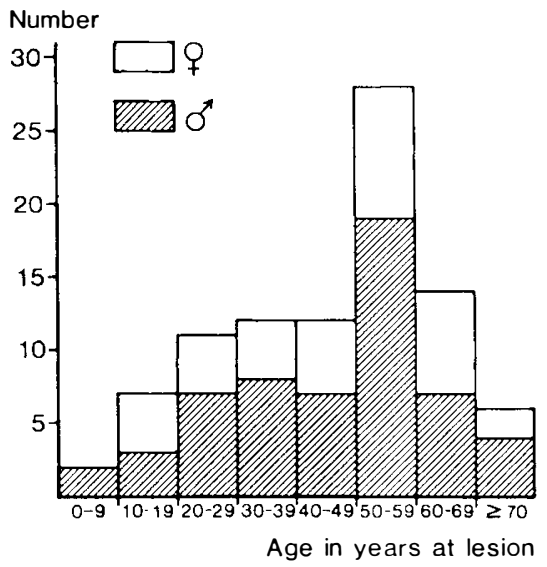

Figure 2 Age distribution of 92 patients with non-traumatic spinal cord lesions.

cysts diagnosed in 3 patients each, and ependymoma, meningioma and angioma in 2 patients each. The vascular group included 6 with thrombosis or embolism of the anterior spinal artery and in 3 cases the spinal cord lesion developed during vascular surgery. 'Other causes' included a wide variety of conditions: after an operation for spondylolithesis, to myelopathy of unknown aetiology.

The male/female ratio among the patients with non-traumatic spinal cord lesions was $1.6(57 / 35)$, i.e. there was no significant sex difference. The age distribution can be seen in Figure 2, from which it can be extracted that the decade with most lesions was $50-59$ years with $30^{\circ}{ }_{\circ}^{\circ}$ of all cases.

\section{Traumatic spinal cord injuries}

Table II shows the causes for traumatic SCI. Nearly half resulted from traffic accidents. The number of injuries due to motor vehicle accidents has decreased in the last decade: 1965-1969: 44 SCI; 1970-1974: 61 SCI; 1975-1979: 32 SCI; 1980-1984: 32 SCI; this change is statistically significant $(p=0.009)$.

Falls to a level below were primarily due to occupational accidents during outdoor employment. Occupational accidents amounted to $18^{\circ}$ \% of all the traumatic SCI.

Twelve per cent of the SCI were caused by either shallow water diving or sporting activities. Sport and leisure activity injuries have been reviewed for 1965-1984, and for the entire 20-year period $11_{\%}^{\circ}(61 / 553)$ of all traumatic SCI were due to these activities, which are listed in Table III (Pedersen, 1985). In 8 of the 34 diving accidents there was knowledge of alcohol intake immediately before. Four of the 5 motor racing accidents happened during motorcycle races. The 4 trampoline accidents were all sustained when jumping minitrampoline, striking the floor or mat during final somersaults (Hammer et al., 1981). The other two gymnastic accidents occurred with jumps over a vaulting horse. 
Table II Cause of traumatic spinal cord injuries (1975-1984)

\begin{tabular}{lrrr}
\hline & Men & Women & Total \\
\hline Traffic accidents & 7 & 3 & 10 \\
$\quad$ Pedestrian & 8 & 1 & 9 \\
Pedal cyclist & 15 & 2 & 17 \\
Moped cyclist & 16 & 1 & 17 \\
Motor cyclist & 35 & & 39 \\
Motor vehicle-driver & 12 & & 25 \\
Motor vehicle-passenger & 7 & & 8 \\
Other & & & $125(47 \%)$ \\
& 100 & 25 & $61(23 \%)$ \\
Traffic accidents in all & 47 & 14 & $9(3 \%)$ \\
Fall to a level below & 7 & 2 & $8(3 \%)$ \\
Fall on the same level & 7 & 1 & $6(2 \%)$ \\
Hit by moving object & 6 & 0 & $15(6 \%)$ \\
Crushing accident & 13 & 2 & $15(6 \%)$ \\
Diving into shallow water & 13 & 2 & $21(8 \%)$ \\
Sporting accident & 6 & 15 & $5(2 \%)$ \\
Attempted suicide & 5 & 0 & $3(1 \%)$ \\
Violence (accidental/malicious) & 2 & 1 & $268(100 \%)$ \\
Other & 206 & 62 & \\
Total & & &
\end{tabular}

Table III Sport and leisure acitivities resulting in spinal cord injuries (1965-1984)

\begin{tabular}{lccc}
\hline & Men & Women & Total \\
\hline Shallow water diving & 31 & 3 & 34 \\
Gymnastics & 3 & 1 & 4 \\
$\quad$ Trampoline & 2 & 0 & 2 \\
$\quad$ Other & 5 & 0 & 5 \\
Motor racing & 3 & 1 & 4 \\
Winter sports & 1 & 2 & 3 \\
Horse-back riding & 2 & 0 & 2 \\
Bicycling & 1 & 1 & 2 \\
Mountain climbing & 4 & 1 & 5 \\
Other & 52 & 9 & 61 \\
Total & & & \\
\hline
\end{tabular}

Attempted suicide being responsible for $8 \%$ of the SCI was the only cause with clear over-representation of women.

The overall male/female ratio in Table II is $3 \cdot 3$ (206/62), but this is a significant decrease $(\mathrm{p}=0.049)$ in comparison with the 10 year period 1965-1974, where the ratio was $5 \cdot 2(239 / 46)$.

The age distribution for the traumatic SCI is shown in Figure 3, and shows a clear maximum from 15-24 years including $40^{\circ}{ }_{\circ}$ of all cases.

Table IV shows the most important mechanism of the trauma in relation to the bony level of lesion.

Of the 268 traumatic SCI $22 \%$ had motor complete tetraplegia, $29 \%$ incomplete tetraplegia, $26 \%$ motor complete paraplegia and the remaining $23 \%$ incomplete paraplegia.

Figure 4 gives the neurological level for all the traumatic SCI. 
Traumatic spinal cord injuries

(1975-84)

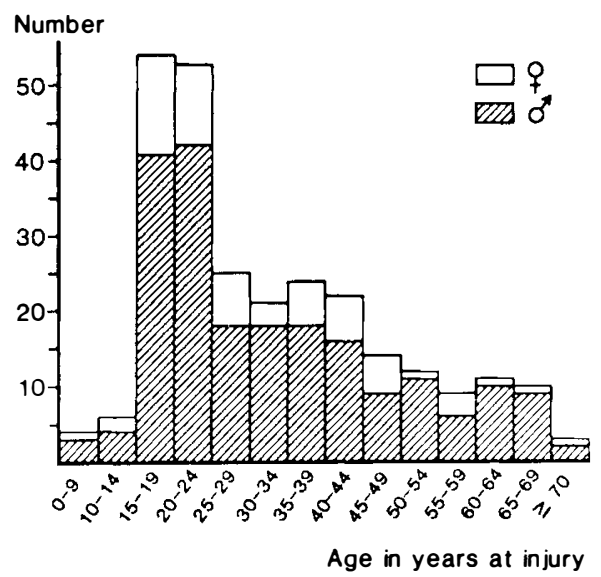

Figure 3 Age distribution at the time of traumatic spinal cord injury (SCI) of 268 patients admitted with SCI.

Table IV The most pronounced mechanism of the trauma in relation to the primary area of the bony lesion

\begin{tabular}{lcccc}
\hline \multirow{2}{*}{ Mechanism of trauma } & \multicolumn{3}{c}{ Bony level of lesion } & Total \\
\hline Flexion & Cervical & Thoracic & Lumbar & 182 \\
Flexion/rotation & 62 & 22 & 18 & 32 \\
Extension & 7 & 20 & 5 & 46 \\
Compression & 43 & 3 & 0 & 49 \\
Direct blow & 13 & 16 & 20 & 18 \\
Uncertain & 0 & 9 & 9 & 21 \\
Total & 11 & 6 & 56 & 268 \\
\hline
\end{tabular}

In Figure 5 is shown the neurological level for the 125 patients, whose SCI was sustained in a traffic accident. This profile shows fewer lesions than in Figure 4. The corresponding profile for falls to a level below is seen in Figure 6, and here the lower lesions are relatively over-represented. On the other hand among falls on the same level 8 of 9 cases resulted in cervical lesions which also were true for all diving accidents (Pedersen, 1985). Considering the 21 attempted suicides, 17 resulted in lesions at or below Th10 corresponding to the fact that the majority of these injuries were sustained in conjunction with a jump from the height.

Tables V-VII give the result of the classification a.m. Frankel et al. (1969) at admission to the neurosurgical departments and at discharge from the rehabilitation hospital in Hornbæk for cervical, thoracic and lumbar injuries. Some comments are added about those patients who were discharged with a worse neurological status than when they were admitted. The thoracic injury was due to an accidental shot at the level of Th3-4, and at admission there was sense of touch distal to a borderline $8 \mathrm{~cm}$ below the inguinal ligaments, but at discharge af ter laminectomy of Th3-5 and rehabilitation the sensibility had completely disappeared below the level of lesion. For the lumbar injuries the pattern was 


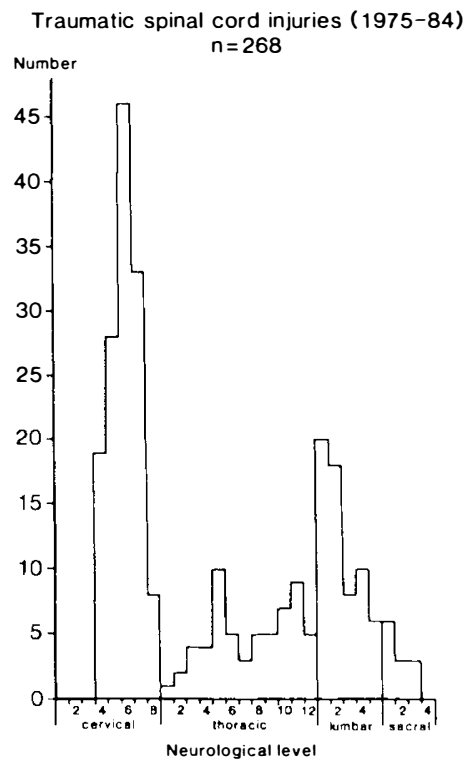

Figure 4 Neurological level, characterised by the most caudal neurologic intact segment, for 268 patients with traumatic spinal cord injuries.

Traffic accidents (1974-85)

$$
n=125
$$

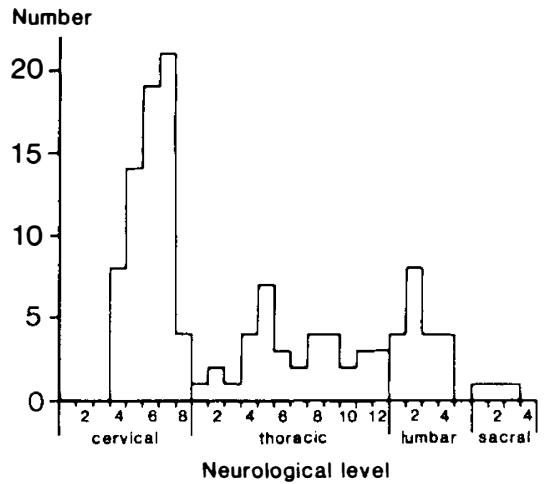

Figure 5 Neurological level (cf. Figure 4) for 125 patients.

Table V Neurological status for 136 cervical injuries

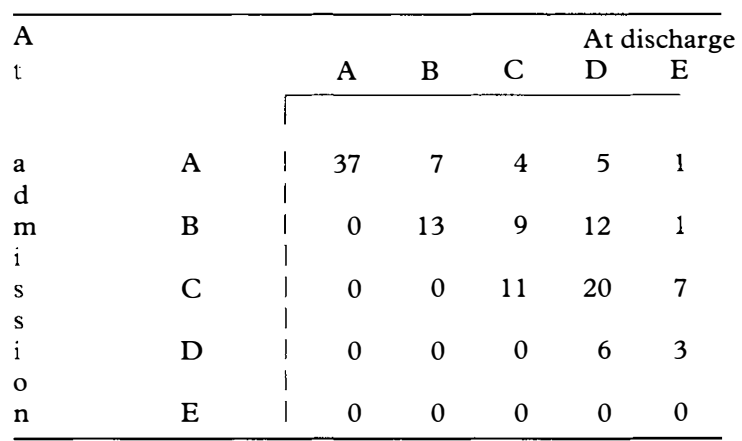


Falls to a level below (1974-85)

$$
n=61
$$

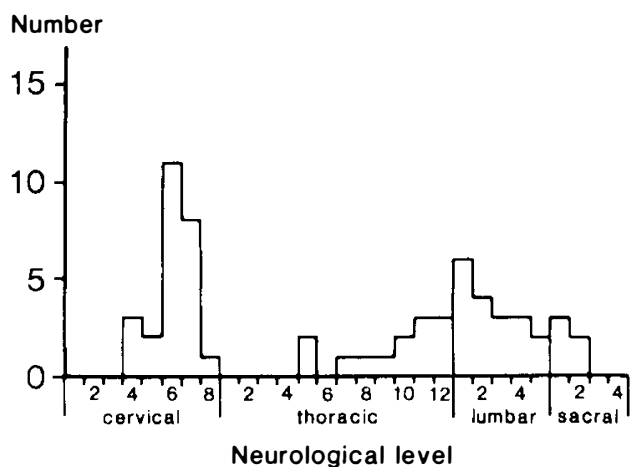

Figure 6 Neurological level (cf. Figure 4) for 61 patients.

Table VI Neurological status for 76 thoracic injuries

\begin{tabular}{|c|c|c|c|c|c|c|c|}
\hline \multirow{2}{*}{\multicolumn{3}{|c|}{ A }} & \multirow[b]{2}{*}{ A } & \multirow[b]{2}{*}{ B } & \multirow[b]{2}{*}{$\mathrm{C}$} & \multicolumn{2}{|c|}{ At discharge } \\
\hline & & & & & & $\mathrm{D}$ & $\mathrm{E}$ \\
\hline a & A & 1 & 49 & 6 & 0 & 1 & 1 \\
\hline $\mathrm{d}$ & & i & & & & & \\
\hline $\mathrm{m}$ & B & i & 1 & 2 & 4 & 0 & 0 \\
\hline $\mathrm{i}$ & & i & & & & & \\
\hline s & $\mathrm{C}$ & i & 0 & 0 & 2 & 3 & 3 \\
\hline s & & I & & & & & \\
\hline $\mathrm{i}$ & $\mathrm{D}$ & 1 & 0 & 0 & 0 & 0 & 4 \\
\hline o & & 1 & & & & & \\
\hline $\mathrm{n}$ & $\mathrm{E}$ & I & 0 & 0 & 0 & 0 & 0 \\
\hline
\end{tabular}

Table VII Neurological status for 56 lumbar (incl. sacral) injuries

\begin{tabular}{lllllll}
\hline A & & & & \multicolumn{3}{c}{ At discharge } \\
t & & A & B & C & D & E \\
a & A & 9 & 0 & 0 & 2 & 0 \\
d & B & 0 & 3 & 2 & 1 & 0 \\
m & C & 1 & 1 & 11 & 7 & 2 \\
i & D & 0 & 0 & 0 & 7 & 6 \\
$\mathrm{~s}$ & E & 0 & 0 & 2 & 1 & 1 \\
\hline o & & & & & &
\end{tabular}

found to be very similar for all cases. All were caused by falls to a level below, and 4 of them as attempted suicides. In all instances motor power was found to decrease within the first days, and decompression operations with stabilisation using Harrington or L-rods were carried out in 4 patients. In one instance, the patient classified with $\mathrm{E}$ both at admission and discharge, the muscle strength decreased after admission but normalised completely during rehabilitation. 
Table VIII Days admitted to neurosurgical department and to the rehabilitation hospital until rehabilitation was concluded. (One motor complete tetraplegia died during the stay in the rehabilitation hospital and this patient is omitted from the calculations in the table).

\begin{tabular}{lcccc}
\hline \multicolumn{1}{c}{$\begin{array}{c}\text { Tetraplegia } \\
\text { Days } \\
\text { admitted }\end{array}$} & $\begin{array}{c}\text { Motor } \\
\text { complete } \\
(\mathrm{n}=57)\end{array}$ & $\begin{array}{c}\text { Motor } \\
\text { incomplete } \\
(\mathrm{n}=78)\end{array}$ & $\begin{array}{c}\text { Motor } \\
\text { complete } \\
(\mathrm{n}=71)\end{array}$ & $\begin{array}{c}\text { Motor } \\
\text { incomplete } \\
(\mathrm{n}=61)\end{array}$ \\
\hline $\begin{array}{l}\text { Neurosurgical dept. } \\
\text { Mean }\end{array}$ & & & & \\
Median & 66 & 62 & 49 & 68 \\
$\quad$ Range & 56 & 45 & 45 & 54 \\
Rehabilitation dept. & $23-254$ & $10-188$ & $7-206$ & $10-242$ \\
$\quad$ Mean & & & & \\
Median & 285 & 199 & 245 & 149 \\
$\quad$ Range & 278 & 172 & 251 & 135 \\
Total & $50-463$ & $11-557$ & $58-404$ & $14-416$ \\
$\quad$ Mean & & & & \\
Median & 351 & 261 & 294 & 217 \\
Range & 329 & 230 & 287 & 196 \\
& $117-533$ & $68-627$ & $113-484$ & $56-487$ \\
\hline
\end{tabular}

Regarding the neurological prognosis as is shown in Tables V-VII, $41 \%$ (111/268) improved from admission to the neurosurgical department until discharge from the rehabilitation hospital. For cervical SCI $51 \%$ improved; $29 \%$ thoracic, and $36 \%$ lumbar. Considering the complete lesions (class A) only, the overall improvement frequency was $22 \%(27 / 122), 31 \%$ for the cervical, $14 \%$ for the thoracic, and $18 \%$ for the lumbar lesions, i.e. a significant $(\mathrm{p}=0.046)$ higher percentage of improvement among the cervical lesions compared to the lower lesions. The corresponding rates for neurological improvement for the incomplete lesions (class B-D) were $58^{\circ}{ }_{0}^{\prime}(84 / 146)$ in all, $63 \%$ for the cervical, $74 \%$ for the thoracic and $40 \%$ for the lumbar lesions. This gives a highly significant better remission of incomplete than complete lesions ( $p<0.00005)$.

In Table VIII is shown the number of days the patients with traumatic SCI were admitted to the neurosurgical department and the rehabilitation hospital in Hornbæk. In general patients with motor complete lesions were hospitalised for longer periods than those with incomplete lesions and tetraplegics spent more days in hospital than paraplegics. But it is also observed that the range for days admitted is very wide. Some patients were discharged prematurely if they could not co-operate in the rehabilitation, e.g. because of severe psychiatric or disciplinary problems.

The incidence computed for Denmark, including Greenland and the Faroe Islands, is $9 \cdot 2$ traumatic SCI per million inhabitants per year, when the average population size for the 10-year period is used as denominator (Statistical Yearbook 1976-1985). This corresponds to a total of 215 new tetraplegics and 260 new paraplegics in the period 1975-1984.

\section{Discussion}

The estimate of the incidence of traumatic SCI of $9 \cdot 2$ per million inhabitants per year is low compared to other studies (Kurtzke, 1975; Kraus, 1980; Wigglesworth, 1987), although the incidence in Greenland, which is part of the 
present material, for the years 1965-1986 was comparably high with 26 per million per year (Pedersen et al., in press). As pointed out by Kraus (1980) incidence rates in different studies can be difficult to compare because of different selection mechanisms. In the study by Kraus et al. (1975) it was found that $38 \%$ of persons with traumatic SCI were dead on arrival at the hospital emergency room or had been taken directly to the county morgue, and in addition $10 \%$ expired during hospitalisation. These death figures corresponded to nearly half of all traumatic SCI. In a study on cervical fractures and dislocations in one of the neurosurgical departments in Denmark (Mosdal and Fedders, 1985) there was within the first 10 days a case fatality rate of $12 \%$ in patients with neurological deficits. In the newly established spinal cord ward within the neurosurgical department, Rigshospitalet, Copenhagen there was a case fatality rate of 7\% in 1985-1986 (Mosdal and Biering-Sørensen, in press). In addition to this our material did not include SCI patients requiring respirator support, nor those with transient paresis, or those who would not be able to co-operate during rehabilitation, and only 4 children were admitted. There may always be some SCI patients who should have been transferred to one of the two rehabilitation hospitals specialising in SCI, but were not. But the incidence estimated in the present study probably reflect the overwhelming majority of patients with traumatic SCI in Denmark, who have serious sequelae.

Turning to the non-traumatic spinal cord lesions it is probably much more uncertain that the rehabilitation hospitals received all those patients who required to be transferred, even when excluding those with progressive spinal cord lesions. An important reason for this is that these patients are admitted to many different hospital departments, while almost all the traumatic SCI patients are admitted to one of the six neurosurgical departments, which traditionally transfer the patients to the two rehabilitation hospitals. The non-traumatic spinal cord lesions constituted about one quarter of all admitted spinal cord lesions, which is a high proportion compared to other reports (Kurtzke, 1975).

The age distribution of the traumatic SCI in the present material is similar to previous studies (Bracken et al., 1981; Burke and Toscano, 1987; Fine et al., 1979-1980; Gjone and Nordlie, 1978-1979; Kurtzke, 1975; Minaire et al., 1978-1979; Stover and Fine, 1987; Wigglesworth, 1987) with the young dominating in contrast to the non-traumatic spinal cord lesions, where 50-59 year olds were in excess.

Our overall male/female ratio of 3.3 is low in comparison to most previous studies (Kurtzke, 1975; Shanmugasundaram, 1987; Stover and Fine, 1987; Wigglesworth, 1987), but a little higher than others (Bracken et al., 1981; Forner et al., 1983; Kraus et al., 1975; Kuhn et al., 1983). As pointed out by Kuhn et al. (1983) the male/female ratio might reflect socioeconomic and cultural differences, and likewise the significant decrease found in our study for this ratio from 1965-1974 to 1975-1984 can be viewed as part of the changing society, for instance with women being more integrated on the labour market. Regarding the non-traumatic spinal cord lesions, no significant difference is observed in the number between males and females, although there is a trend towards more men than women, and we have no explanation for this.

Kurtzke (1975) summarised from the available literature the causes of trau- 
matic SCI: $\frac{1}{2}$ due to traffic accidents, $\frac{1}{4}$ to falls and $\frac{1}{4}$ to all other causes, which is true for our material as well (cf. Table II). But again there will be great differences depending on the country/locality considered, e.g. in Greenland there were virtually no traffic accidents (Pedersen et al., in press), comparable to high frequencies of falls in Burma (Toe, 1978-1979) and India (Shanmugasundaram, 1987).

Regarding the traffic accidents we found for those involving motor vehicles a significant decrease in the number from the mid-seventies, which coincided with the introduction of general speed limits in 1973 and compulsory use of seat belts on the front seats in 1976. A similar experience has been reported from Australia (Burke, 1977), although within recent years there has been an increased incidence of SCI, presumably because of more road accidents (Burke and Toscano, 1987; Wigglesworth, 1987).

Occupational accidents made up $18 \%$ of all traumatic SCI in our series, which is similar to previous studies (Burke, 1977; Carter, 1977; Cheshire, 1968-1969; Kurtzke, 1975; Sutton, 1973), although Tator and Edmonds (1979) reported a frequency of about $30 \%$.

Sport and leisure activities in the 20 -year period $1965-84$ caused $11 \%$ of all traumatic SCI. This is similar to the frequency in other countries (Burke, 1977; Frankel et al., 1969; Girard et al., 1980; Griffiths, 1980; Kraus et al., 1975; Kurtzke, 1975; Ohry and Rozin, 1982; Steinbrück and Paeslack, 1980; Stover and Fine, 1987), and as in most other series diving into shallow water was the commonest cause. The danger of severe injuries associated with the use of trampoline has previously been stressed (Ellis et al., 1960; Krawitz, 1978; Steinbrück and Paeslack, 1978), and in Denmark this knowledge resulted in 1981 in the ban on usage of trampolines in schools.

The fact that more women than men sustained their SCI because of attempted suicide in particular due to jumps, is in agreement with previous published reports (Chen and Lien, 1985; Girard et al., 1980; Girard et al., 1983; Kuhn et al., 1983). The relative high frequency of attempted suicides in our series compared to most other studies is probably due to the openness and thoroughness of the research into suicides and attempted suicides performed within Denmark. Of course socioeconomic and cultural factors are also of importance, as is demonstrated in the study from Greenland (Pedersen et al., in press), where not less than one quarter of all traumatic SCI were caused by attempted suicide.

Violence, gunshot and stab wounds, on the other hand, is rare in our material when compared with others (Carter, 1977; Clifton, 1983; Key and Retief, 1970; Kraus et al., 1975; Kurtzke, 1975; Norrell and Brocklehurst, 1973).

The neurological level of SCI (cf. Figs 4-6) reflects to a certain degree the cause of injury (Chen and Lien, 1985; Fife and Kraus, 1986; Frankel et al., 1969; Kraus et al., 1975; Kurtzke, 1975). Diving into shallow water usually resulting in tetraplegia is a clear example. Our experience with slightly more cervical than thoracic/lumbar injuries among traffic accidents has been observed previously (Carter, 1977; Chen and Lien, 1985; Fife and Kraus, 1986; Frankel et al., 1969; Kurtzke, 1975), and likewise was it previously found that falls cause paraplegia rather than tetraplegia (Carter, 1977; Chen and Lien, 1985; Fife and Kraus, 1986; Frankel et al., 1969; Girard et al., 1980; Kurtzke, 1975). The present study additionally showed that falls on the same level most often 
resulted in cervical lesions, while it was falls to a level below which caused more caudal lesions.

The number of tetraplegics equalled that of paraplegics (including conuscauda equina lesions), which was also found by others (Chen and Lien, 1985; Kraus et al., 1975; Kurtzke, 1975; Stover and Fine, 1987), unlike some series where two-limb involvement was twice as frequent as four (Gehrig and Michaelis, 1968; Kurtzke, 1975).

The neurological status classified a.m. Frankel et al. (1969) was in the whole material found to improve in $41 \%$, which is similar to the $36 \%$ reported by Frankel et al. (1969), but much higher than the $20 \%$ improvement found by Kraus et al. (1975). This difference by Kurtzke (1975) was explained to reflect the complete rehabilitaion in the former, and the acute short term care in the latter study, but it is also worth mentioning that the classifications were different. Otherwise our results confirm these two studies, and those from Australia (Bedbrook and Sakae, 1982; Burke and Murray, 1976) in that incomplete lesions are more likely to improve than complete, regardless of level. In addition our material confirms the findings of Frankel et al. (1969) regarding the better chance for neurological improvement in complete cervical compared with complete thoracic/lumbar lesions. Considering these prognostic evaluations certain reflections shall be brought forward. Firstly might the initial neurological status judged at the admission to the neurosurgical department be different from the status at the site of injury (Toscano, 1988); i.e. changes could occur in course of transportation, not least for those patients who were admitted from Greenland (Pedersen et al., in press). Secondly, the initial determination can be a problem if the patient at that time has difficulty in co-operation, i.e. lesions which at this time were found to be complete (class A) in reality were not so. If this is true, then our results regarding remission will be too optimistic. Finally, comments regarding the classification itself. Class $\mathrm{D}$ is relatively wide, meaning that significant improvement will not be registered, e.g. a tetraparetic person who at admission could use the one lower extremity, but both at discharge and otherwise had unchanged pareses in trunk and arms, will remain in class D despite this significant motor improvement. For the lower lesions the distinction between class $\mathrm{C}$ and $\mathrm{D}$, in particular, can be difficult. It shall be stressed that Frankel et al. (1969) in their paper point out that this classification is relatively crude.

The duration of hospitalisation (cf. Table VIII) in the present study is longer than those previously presented (Botterell et al., 1975; Chen and Lien, 1985; Stover and Fine, 1987; Wilcox et al., 1970). In particular the data from Chen and Lien (1985) show, to our opinion, very short admissions, but it is not obvious, whether the complete rehabilitation period is included. On the other hand compared with the previous study on paraplegics by Eskesen (1970) from the rehabilitation hospital in Hornbæk covering the years 1954-1967, we can ascertain a clear decrease in the average number of days admitted to the rehabilitation hospital. This development can probably be ascribed to fewer complications in the acute and subacute treatment period. In addition it should be noted that discharge from the rehabilitation hospital in certain instances is delayed because of social circumstances, in particular lack of suitable housing facilities. This results in an increased number of days in hospital, than is necessary. 


\section{References}

BEDBROOK GM, SAKAE T 1982 A review of cervical spine injuries with neurological dysfunction. Paraplegia 20:321-333.

Botterell EH, Jousse AT, KRAus AS, et al. 1975 A model for the future care of acute spinal cord injuries. Canadian fournal of Neurological Sciences 3:361-380.

Bracken MB, Freeman DH JR, Hellenbrand K 1981 Incidence of traumatic hospitalized in spinal cord injury in the United States 1970-1977. American fournal of Epidemiology 113:615-622.

BURKE DC 1977 Spinal cord injuries, 1976. Australia New Zealand fournal of Surgery 47:166170.

BURKE DC, MURRAY DD 1976 The management of thoracic and thoraco-lumbar injuries of the spine with neurological involvement. The fournal of Bone and foint Surgery 58-B:72-78.

BURKE DC, TosCano J 1987 Incidence and distribution of spinal injury. Menzies Technical Report 1:13-47.

CARTER RE JR 1977 Etiology of traumatic spinal cord injury: statistics of more than 1,100 cases. Texas Medicine 73:61-65.

Chen CF, Lien IN 1985 Spinal cord injuries in Taipei, Taiwan 1978-81. Paraplegia 23:364370.

Cheshire DJE 1968-1969. The complete and centralised treatment of paraplegia. Paraplegia 6:59-73.

Clifton GL 1983 Spinal cord injury in the Houston-Galveston area. Texas Medicine 79:55-57.

Ellis WG, Green D, Holzaepfel NR, et al. 1960 The trampoline and serious neurological injuries. A report of five cases. The fournal of the American Medical Association 174:16731676.

ESKESEN B 1970 Spinal paraplegia. A follow-up investigation of medical and social rehabilitation. Ugeskrift for Lager 132:849-854. (in Danish with summary in English).

FIFE D, KRAUS J 1986 Anatomic location of spinal cord injury. Relationship to the cause of injury. Spine 11:2-5.

Fine PR, Kuhlemeier KV, DeVivo MJ, Stover SL 1979-1980 Spinal cord injury: an epidemiologic perspective. Paraplegia 17:237-250.

Forner JV, Miro R, Delgado M, Giner MF, Gonzalez CV, Bejar MD 1983 The female paraplegic in Spain: preliminary report. Paraplegia 21:176-183.

Frankel HL, HaNCOCK DO, Hyslop G et al. 1969 The value of postural reduction in the initial management of closed injuries in the spine with paraplegia and tetraplegia. Paraplegia 7:179192.

Gehrig R, Michaelis LS 1968 Statistics of acute paraplegia and tetraplegia on a national scale. Paraplegia 6:93-95.

Girard R, Minaire P, Castanier M, Berard E, Perrineriche B 1980 Spinal cord injury by falls: comparison between suicidal and accidental cases. Paraplegia 18:381-385.

Girard R, Boisson D, Depassio J, BouCAnd MH, et al. 1983 The female paraplegic: a statistical survey. Paraplegia 18:149-153.

GJONE R, NORDLIE L 1978-1979 Incidence of traumatic paraplegia and tetraplegia in Norway: a statistical survey of the years 1974 and 1975. Paraplegia 16:88-93.

GrIFFITHS ER 1980 Spinal injuries from swimming and diving treated in the spinal department of Royal Perth Rehabilitation Hospital: 1959-1978. Paraplegia 18:109-117.

Hammer A, Schwartzbach AL, DarRe E, Osgood O 1981 Severe neurological damage resulting from trampoline jumps. Ugeskrift for Lager 143:2970-2974 (in Danish with summary in English).

HoldwORTH F 1970 Fractures, dislocations, and fracture-dislocations of the spine. The fournal of Bone and foint Surgery 52-A:1534-1551.

Key AG, Retief PJM 1970 Spinal cord injuries. An analysis of 300 new lesions. Paraplegia 7:243-249.

KRAUS JF 1980 Injury to the head and spinal cord. The epidemiological relevance of the medical literature published from 1960 to 1978. Fournal of Neurosurgery 58:S3-S10.

KraUs JF, Franti CE, RIgGins RS, et al. 1975 Incidence of traumatic spinal cord lesions. fournal of Chronic Diseases 28:471-492.

KRAWITZ H 1978 Problems with the trampoline: Too many cases of permanent paralysis. Pediatric Annals 7:728-729.

KuHN W, ZäCH GA, KöChlin PH, URWYLER A 1983 Comparison of spinal cord injuries in females and in males, 1979-81 Basle. Paraplegia 21:154-160.

KURTZKE JF 1975 Epidemiology of spinal cord injury. Experiment al Neurology 48:163-236.

Minaire P, Castanier M, Girard R, et al. 1978-1979 Epidemiology of spinal cord injury in the Rhône-Alpes region, France, 1970-75. Paraplegia 16:76-87.

MosDAL C, FEDDERS O 1985 Fractura et dislocatio columna cervicalis. Ugeskrift for Lager 147:1387-1392 (in Danish with summary in English). 
Mosdal C, BIERING-SørRensen F Organisation and management of a spinal cord injury department. First two year's patients. Ugeskrift for Lager (in press).

NorRell H, BrodklehURST G 1973 Spinal injuries in Kentucky. The fournal of Kent ucky Medical Association 71:586-589.

OHRY A, Rozin R 1982 Spinal cord injuries resulting from sport. The Israeli Experience. Paraplegia 20:334-338.

PEDERSEN V 1985 Spinal cord injuries resulting from sport and leisure accidents during the period 1965-1984. Review of a material from a 20 year period in the Physiurgic Hospital in Hornbæk. Ugeskrift for Lager 147:4236-4238 (in Danish with summary in English).

Pedersen V, Clausen S, Biering-Sørrensen F 1988 The prognosis in cervical cord lesions. Ugeskrift for Lager 150:1162-1166 (in Danish with summary in English).

Pedersen V, Müller PG, Biering-SørRensen F 1988 Traumatic spinal cord injuries in Greenland. Paraplegia (in press).

ShanMUgASUNDARAM TK 1987 Madras paraplegia project 1978-1987. Challenge and the response. Madras.

Statistical Yearbook 1976-1985. Vol. 80-89. Danmarks statistik, Copenhagen 1976-1985.

SteINBRÜCK K, PAesLaCK V 1978 Trampolinspringen-ein Gefährlicher Sport? Münch Med Wochenschr 120:985-988.

STEINBRÜCK K, PaESlaCK V 1980 Analysis of 139 spinal cord injuries due to accidents in water sports. Paraplegia 18:86-93.

StOVer SL, FINE PR 1987 The epidemology and economics of spinal cord injury. Paraplegia 25:225-228.

SuTTON NG 1973 Injuries of the spinal cord. Butterworths pp. 79-85.

TATOR CH, Edmonds VE 1979 Acute spinal cord injury: Analysis of epidemiologic factors. The Canadian fournal of Surgery 22:575-578.

ToE T 1978-79 Spinal injuries in Rangoon, Burma. Paraplegia 16:118-120.

TosCano J 1988 Prevention of neurological deterioration before admission to a spinal cord injury unit. Paraplegia 26:143-150.

WIgGLESWORTH EC 1987 Towards solution. A literature review. Menzies Technical report 1:7585.

Wilcox NE, STAufFer ES, Nickel VL 1970 A statistical analysis of 423 consecutive patients admitted to the spinal cord injury center, Rancho Los Amigos Hospital, 1 January 1964, through 31 December 1976. Paraplegia 8:27-35. 